\title{
P.В. Ушаков
}

\section{КРИТЕРИИ, ПОДЛЕЖАЩИЕ ОЦЕНКЕ ПРИ РЕАЛИЗАЦИИ ЗАКОННЫХ ИНТЕРЕСОВ ОСУЖДЕННЫХ К ЛИШЕНИЮ СВОБОДЫ}

\begin{abstract}
Проводится анализ критериев, подлежащих оценке в ходе процедуры рассмотрения вопроса о реализации законных интересов осужденных к лишению свободы. Помимо закрепленных в законодательстве характеристик, автором предлагается включать в оценку и учет такие критерии, как наличие и характер социально-полезных связей осужденного, а также уровень его антисоциальной направленности, оцениваемый по состоянию криминальной зараженности и вовлеченности.
\end{abstract}

Ключевые слова: осужденные, критерии оценки, криминальная зараженность, криминальная вовлеченность, сочиальнополезные связи.

Вопрос четкого определения перечня критериев, подлежащих оценке при реализации законных интересов осужденных, и, в ряде случаев, его законодательного закрепления длительное время является дискуссионным как в теории уголовно-исполнительного права, так и в практике исполнения и отбывания наказания в виде лишения свободы. Рассмотрение указанных аспектов представляется особенно актуальным ввиду часто встречающихся расхождений в определении характеристик, подлежащих оцениваю компетентными органами.

Большинство ученых-пенитенциаристов едины во мнении, что главным условием реализации законных интересов осужденных является оценка поведения последних. Анализ российского законодательства, а также судебной практики и личных дел осужденных показал, что в действительности, помимо поведения, существует довольно широкий перечень критериев, подлежащих оценке в ходе реализации законных интересов осужденных к лишению свободы. Одни критерии прямо закреплены в законодательных актах, другие, не имея такого закрепления, широко используются и имеют устоявшуюся практику применения. Тем не менее на сегодняшний день отсутствует единая логично выстроенная система таких характеристик.

Поскольку такие характеристики выступают как совокупность условий, при наличии которых происходит реализация законного интереса, нами предлагается представлять их в качестве определенных способствующих (реализации законного интереса) обстоятельств.

Весь массив таких способствующих обстоятельств предлагается разделить на две основные группы:

- обстоятельства внутреннего характера (связаны с самим осужденным и, в той или иной мере, зависят от его особенностей, стремлений, действий и поведения). Примером таких обстоятельств могут служить правопослушное поведение осужденного, положительно характеризующие материалы, отсутствие исковой задолженности и др.;

- обстоятельства внешнего характера (не имеют отношения к личности осужденного, однако способны влиять на возможность предоставления определенных благ). В качестве такого обстоятельства выступает, главным образом, наличие экономической или техни- ческой возможности учреждения реализовать законный интерес.

Оформление учитываемых обстоятельств внутреннего характера в системном виде довольно затруднено ввиду их многообразия и, в ряде случаев, отсутствия закрепления в законодательстве. Наличие широкого спектра таких обстоятельств обусловлено индивидуализированным подходом к рассмотрению того или иного ходатайства о предоставлении законного интеpeca. Это делает невозможным отражение их исчерпывающего перечня в нормах права.

Однако анализ ряда норм уголовного и уголовноисполнительного законодательства позволяет выделить некоторые общие критерии, относимые к учитываемым обстоятельствам внутреннего характера, способствующим реализации некоторых законных интересов осужденных.

Так, в положениях ч. 2.2 ст. 78 УИК РФ (законный интерес на изменение вида исправительного учреждения); ч. 4.1 ст. 79 УК РФ, ч. 2 ст. 175 УИК РФ (законный интерес на условно-досрочное освобождение от отбывания наказания) и ч. 4 ст. 80 УК РФ, ч. 3, ч. 3.1 ст. 175 УИК РФ (законный интерес на замену неотбытой части наказания более мягким видом наказания) закреплены схожие критерии, подлежащие оценке и учитываемые при решении вопроса о предоставлении указанных законных интересов:

- поведение осужденного;

- отношение осужденного к учебе и труду в течение всего периода отбывания наказания;

- наличие поощрений и взысканий;

- отношение осужденного к совершенному деянию;

- частичное или полное возмещение причиненного ущерба (или иное заглаживание вреда, причиненного в результате преступления);

- прохождение курса лечения и отношение к применению принудительных мер медицинского характера со стороны осужденного, страдающего расстройством сексуального предпочтения (педофилией), не исключающим вменяемости, и совершившего в возрасте старше восемнадцати лет преступление против половой неприкосновенности несовершеннолетнего, не достигшего четырнадцатилетнего возраста. 
Некоторые авторы считают, что данные характеристики отражают наиболее общие позиции оценки степени исправления осужденного, которая, по мнению ученых, необходима для реализации не только представленной группы, но и большинства иных законных интересов. Исходя из этого, предлагается закрепить указанные критерии в ст. 9 УИК РФ в качестве единых характеристик, учитываемых при определении степени исправления осужденных [1, с. 66-67].

С одной стороны, мы полагаем, что такое закрепление может оказаться полезным для практики ввиду того, что позволило бы использовать единообразный оценочный подход при решении вопроса о реализации того или иного законного интереса. Сказанное подтверждается и мнением 42 \% опрошенных осужденных, отметивших, что детальная проработка и закрепление условий и критериев оценки характеризующих материалов поспособствуют совершенствованию механизма реализации законных интересов.

С другой стороны, возникает вопрос: насколько обоснованным было бы применение перечня характеристик, определяющих степень исправления осужденного, в решении вопросов о реализации законных интересов, не предусматривающих такого определения?

Дело в том, что положения подавляющего большинства норм, отражающих законные интересы осужденных, не предполагают оценку степени исправления осужденного в качестве основания реализации законного интереса. Определение степени исправления осужденного может оказаться полезным, главным образом, при решении вопроса о предоставлении условно-досрочного освобождения и, частично, о замене неотбытой части наказания более мягким видом, что, безусловно, продиктовано особенностями указанных институтов. В иных же случаях объем предоставляемых осужденному благ не требует столь широкого набора предъявляемых требований, подлежащих оценке. Следовательно, предложение о закреплении в особенной части УИК РФ единого перечня характеристик, учитываемых при определении степени исправления осужденных, при ныне существующем подходе не находит свою актуальность.

На наш взгляд, гораздо целесообразнее говорить о некоем едином перечне критериев, подлежащих оценке при реализации законных интересов осужденных к лишению свободы. Отличие такой позиции заключается в том, что характеристики, образующие представленный перечень, могли бы использоваться как в совокупности (например, при определении степени исправления осужденного), так и рассматриваться самостоятельно (при решении вопроса о реализации того или иного законного интереса).

При анализе законодательства, судебной практики и документов, используемых в деятельности органов и учреждений УИС, мы пришли к выводу, что рассматриваемый выше перечень может быть вполне обоснованно дополнен еще рядом учитываемых критериев, подлежащих оценке.

Одним из таких критериев, на наш взгляд, должна выступать такая характеристика, как поддержание и характер социально-полезных связей, к которым сле- дует отнести отношения с родственниками, а в случае их отсутствия - с иными близкими людьми.

Во-первых, семья в подавляющем большинстве случаев является действенным стимулом для положительного изменения поведения осужденного и имеет достаточно высокий ресоциализационный потенциал [2, c. $175-176]$.

Во-вторых, в случае реализации законного интереса, связанного с досрочным освобождением осужденного из мест лишения свободы, семья может выступать в качестве определенного сдерживающего фактора, тормозящего возможные противоправные проявления осужденного в течение оставшейся не отбытой части наказания.

В-третьих, в случае реализации законных интересов, связанных со значительным изменением объема правового статуса осужденного (изменение вида ИУ, изменение условий отбывания наказания), учет семейных отношений необходим для выявления осужденных, которым наиболее необходимо изменение объемов предоставляемых краткосрочных и длительных свиданий. К примеру, при решении вопроса об изменении условий отбывания наказания, при равной степени исправления, осужденный, имеющий семью и детей, на наш взгляд, должен иметь приоритет.

Отношения осужденных с семьей, как учитываемый критерий, указаны в ряде судебных и нормативных документов.

Так, в п. 27 Постановления Пленума Верховного Суда РФ от 29.05.2014г. № 9 «О практике назначения и изменения судами видов исправительных учреждений» (далее - Постановление Пленума ВС № 9) среди критериев, на которых должен быть основан вывод о положительной характеристике осужденного, указывается поддержание отношений с родственниками. Вместе с тем в П. 5 Постановления Пленума Верховного Суда РФ от 21.04.2009 г. № 8 «О судебной практике условно-досрочного освобождения от отбывания наказания, замены неотбытой части наказания более мягким видом наказания» (далее - Постановление Пленума ВС № 8) при решении вопроса о предоставлении несовершеннолетнему осужденному УДО суду необходимо учитывать его связи с родственниками в период отбывания наказания. В п. 3.1 Обзора судебной практики условно-досрочного освобождения от отбывания наказания, утвержденного Президиумом Верховного Суда Российской Федерации 29 апреля 2014 г., указано, что при оценке поведения осужденного судами учитывался ряд оценочных критериев, в том числе поддержание осужденным отношений с родственниками. Безусловно, на наш взгляд, суду в таких случаях следует учитывать не только факт поддержания отношений и связей осужденного с родственниками, а также характер и направленность таких отношений и связей.

Родственные связи должны учитываться, в том числе и при реализации законного интереса на помилование. Так, в п. 5 Положения о порядке рассмотрения ходатайств о помиловании в Российской Федерации (утв. Указом Президента РФ от 28 декабря 2001 г. № 1500) одним из прилагаемых к ходатайству о помиловании документов указана анкета с указанием био- 
графических данных осужденного и сведений о его семейном положении.

Безусловно, при оценке характера отношений осужденного с родственниками или иными близкими людьми такая оценка не должна быть односторонней. Представляется целесообразным получение подтверждающей информации о положительной характеристике родственников осужденного из органов внутренних дел по месту жительства, наличия необходимых условий для проживания, в случае отсутствия постоянного места жительства у осужденного, а также о согласии родственников принять осужденного в таком случае.

Вместе с тем отсутствие семьи, родственников или иных близких людей у осужденного, а следовательно, и отсутствие социальнополезных связей, не должно служить основанием для отказа в реализации того или иного законного интереса. Наличие и характер социальнополезных связей всего лишь учитываются и, наряду с иными критериями, образуют целостную картину, отражающую характеристику личности осужденного.

Таким образом, можно заключить, что характер отношений с родственниками или иными близкими лицами как оценочный критерий в настоящее время активно используются в практике решения вопросов о реализации тех или иных законных интересов осужденных. Вместе с тем ряд нормативных документов прямо предписывает компетентным органам такие действия. Думается, что указанные обстоятельства могут служить достаточным основанием для включения социальнополезных связей в перечень характеристик, учитываемых при определении степени исправления осужденных.

При определении степени исправления осужденного, помимо наличия и характера социальнополезных связей, на наш взгляд, необходимо учитывать и уровень его антисоциальной направленности.

Данное предложение объясняется тем, что зачастую правопослушное поведение осужденных является всего лишь мимикрией - ими могут соблюдаться все формальные критерии, необходимые для признания эффективности их исправления, однако реальная мотивация останется в сфере криминально-ориентированных интересов. Иными словами, у осужденного может быть сформировано определенное установочное поведение в местах лишения свободы, ориентированное только на получение определенного блага (в том числе путем реализации законного интереса), подменяющее собой истинное желание встать на путь исправления и избежать совершения преступлений в дальнейшем.

Высказанное содержит в себе следующие риски:

- при реализации законных интересов на досрочное освобождение вполне вероятен рецидив преступлений. Осужденные, имеющие высокий уровень криминальной зараженности и вовлеченности, в основном взаимодействуют внутри сложившейся микрогруппы, образуя прочные связи, которые не утрачиваются и после освобождения из исправительного учреждения. Зачастую такие связи на свободе приобретают более криминально-ориентированный характер, а поэтому повышается риск повторного совершения преступлений досрочно освобожденными, в том числе в период не отбытой части наказания;

- при реализации законных интересов, связанных с нахождением за пределами исправительного учреждения, повышается вероятность совершения правонарушений, в том числе связанных с негативным влиянием на обстановку в исправительном учреждении. Так, например, нахождение за пределами исправительного учреждения может быть использовано как для осуществления самостоятельных противоправных действий, так и для координации противоправных действий иных лиц (например, осужденный может выступать в качестве некоего «связного» и др.);

- при реализации законных интересов на изменение условий отбывания наказания возможна угроза пропаганды криминальных ценностей среди других осужденных или иного негативного влияния на обстановку в исправительном учреждении. На практике нередки случаи, когда осужденные отрицательной направленности намеренно добиваются перевода в облегченные условия отбывания наказания, преследуя определенные противоправные цели: дестабилизацию оперативной обстановки в отряде, принуждение иных осужденных к пополнению так называемого «общака», организацию азартных игр в отряде и т.п. Вместе с тем изменение вида исправительного учреждения, главным образом на колонию-поселение, зачастую используется в целях организации каналов проникновения запрещенных предметов на территорию исправительного учреждения, особенно если перевод происходит в участок колонии-поселения, функционирующий при той же исправительной колонии, в которой ранее отбывал наказание осужденный.

С целью недопущения указанных и иных противоправных эксцессов нами предлагается при решении вопроса о реализации законных интересов осужденных, помимо других характеристик, оценивать и учитывать в том числе и уровень криминальной зараженности и вовлеченности осужденного. Оценка предложенных показателей необходима в целях выявления искренности мотивации осужденного к поддержанию правопослушного поведения и возможных рисков отклонения от него.

Следует оговориться, что в представленную оценку должны входить не только такие тривиальные позиции, как, например, заинтересованность осужденного «творческими» элементами криминальной субкультуры (имеется в виду криминальный фольклор, жаргон и др.), но, прежде всего, непосредственная степень поддержания противоправного образа жизни, а также участие в деятельности, связанной с противоправными и деструктивными проявлениями.

Под криминальной зараженностью в психологии понимается морально-нравственное отношение к криминальной и формальной государственной нормативным системам [3, с. 104-107]. Таким образом, уровень криминальной зараженности воспринимается как психологическая характеристика личности.

В соответствии с Инструкцией по организации деятельности психологической службы уголовноисполнительной системы, утвержденной Приказом 
Минюста РФ от 12 декабря 2005 г. № 238, одной из методик, применяемых к осужденным, является Комплексное исследование личности осужденного, непосредственно предназначенное для выявления уровня криминальной зараженности. Она представляет собой многофакторный опросник для комплексной диагностики различных видов девиантного и делинквентного поведения и рекомендована для диагностики криминальной зараженности лиц, находящихся в пенитенциарных учреждениях.

Данные по результатам представленного обследования отражаются в психологической характеристике осужденного, которая, в том числе, входит в число характеризующих материалов, предоставляемых для оценки компетентными органами. Таким образом, у психологических служб учреждений УИС есть все необходимые возможности для выявления уровня криминальной зараженности осужденных, которые в настоящее время активно используются.

Под уровнем криминальной вовлеченности осужденного мы предлагаем понимать показатель, отражающий глубину и характер связей с криминально-ориентированными элементами, а равно с группами осужденных отрицательной направленности, а также намерения по совершению действий, представляющих как собственно противоправные деяния, так и оказание иного негативного влияния на общественные отношения.

Под последним могут пониматься активные действия, направленные на пропаганду криминальных идей и ценностей, создание негативного образа УИС, совершение провокаций в отношении сотрудников правоохранительных органов и органов УИС, активные призывы к совершению противоправных действий, организация и активное участие в группах осужденных отрицательной направленности и тому подобные.

Необходимо заметить, что к осужденным, вынашивающим противоправные намерения, должны применяться меры предупреждения в соответствии с положениями Инструкции по профилактике правонарушений среди лиц, содержащихся в учреждениях уголовно-исполнительной системы, утвержденной Приказом Минюста РФ от 20 мая 2013 г. № 72. Пункт 24 настоящей Инструкции устанавливает исчерпывающий пере- чень осужденных, которых необходимо подвергать профилактическому учету.

Однако постановка на учет в большинстве случаев подтверждает только сам факт склонности осужденного к совершению того или иного эксцесса. По ряду объективных причин применение мер индивидуальной профилактики зачастую носит формальный характер и имеет низкую эффективность. Именно поэтому, на наш взгляд, невозможно судить об уровне криминальной вовлеченности только по показателю проводимой индивидуально-профилактической работы.

Сведения о криминальной вовлеченности осужденного, независимо от факта постановки (либо не постановки) на профилактический учет, должны добываться и аккумулироваться сотрудниками оперативного подразделения учреждения. Ввиду закрытости средств и методов оперативно-розыскной деятельности, мы не можем детально охарактеризовать процесс получения такой информации и ее содержание, однако думается, что она могла бы предоставляться в виде справки, не содержащей сведений, раскрывающих государственную тайну.

Представляется, что условная градация уровней криминальной вовлеченности может быть представлена в следующем виде:

- криминальная вовлеченность отсутствует;

- слабый уровень криминальной вовлеченности;

- частичная криминальная вовлеченность;

- устойчивая криминальная вовлеченность.

Сведения о криминальной зараженности и вовлеченности могут существенно дополнить картину, отражающую степень исправления осужденного и во многом помочь компетентным органам в принятии решений о реализации законного интереса.

Таким образом, поддержание и характер социальнополезных связей осужденных, а также уровень их криминальной вовлеченности и зараженности выступают в качестве самостоятельных характеристик, оцениваемых при реализации законных интересов осужденных к лишению свободы. Рассмотренные критерии должны оцениваться и учитываться наряду с иными характеризующими материалами и могут быть включены в перечень критериев, подлежащих оценке при реализации законных интересов осужденных к лишению свободы.

\section{ЛИТЕРАТУРА}

1. Голодов П.В., Рудаков А.М. Критерии оценки поведения осужденных в уголовно-исполнительном законодательстве: вопросы систематизации // Вестник института: преступление, наказание, исправление. 2016. № 3 (35). С. 64-67.

2. Финаева А.Г. Ресоциализационный потенциал семьи осужденного // ИСОМ. 2012. № 4. 132 с.

3. Шатровой О.В., Канчурина А.А. Подходы к пенитенциарному воспитанию как составляющей социально-психологической безопасности // Молодой ученый. 2014. № 18. С. 104-107. URL: https://moluch.ru/archive/77/13221/ (дата обращения: 11.01.2018).

\section{CRITERIA TO BE ASSESSED IN EXERCISING LEGITIMATE INTERESTS OF PERSONS SENTENCED TO DEPRIVA-} TION OF LIBERTY

Ugolovnaya yustitsiya - Russian Journal of Criminal Law, 2018, no. 12, pp. 108-112. DOI 10.17223/23088451/12/21

Roman V. Ushakov, Academy of the Federal Penitentiary Service of Russia (Ryazan, Russian Federation). E-mail: ushakovrv@list.ru

Keywords: convicts, assessment criteria, criminal exposure, criminal involvement, socially useful links.

The article analyses a number of criteria to be assessed and requirements imposed on a convicted person in the course of deciding on the exercising the majority of special legitimate interests. The problems in exercising the legitimate interests of convicts are mainly caused by an indefinite wideness of the list of such criteria, as well as by the absence of a unified approach to their assessment and application. The conducted analysis of the Russian criminal and penal enforcement legislation revealed a single list of such criteria. At the same 
time, the study of the judicial practice materials on the exercising the legitimate interests of persons sentenced to deprivation of liberty and their personal files showed that the list considered can be reasonably supplemented by several additional criteria. Firstly, it is advisable to assess and take into account the degree and nature of socially useful links of the person sentenced to deprivation of liberty. This approach is based on the significant social rehabilitation potential of a family, as well as the possibility of expanding the circle of people whose interests can be exercised; moreover, the need to regard socially useful links as a criterion to be assessed when deciding on the exercising certain legitimate interests is indicated by a number of regulations and court decisions. Secondly, the characterising materials are proposed to reflect the convict's antisocial orientation, which is assessed by the person's levels of criminal exposure and criminal involvement. The criminal exposure of a convicted person should be understood as their psychological attitude to the unlawful way of living; the level of criminal involvement indicates the depth and nature of connections with criminal elements, as well as the presence of illegal intentions. In the aauthor's opinion, the considered criteria should be assessed and adhered to along with other characterising materials; they can be included in the appropriate list of criteria taken into account when exercising the legitimate interests of persons sentenced to deprivation of liberty.

\section{References}

1. Golodov, P.V. \& Rudakov, A.M. (2016) Kriterii otsenki povedeniya osuzhdennykh v ugolovno-ispolnitel'nom zakonodatel'stve: voprosy sistematizatsii [Criteria for assessing the behaviour of convicts in the penal legislation: questions of systematization]. Vestnik instituta: prestuplenie, nakazanie, ispravlenie. 3 (35). pp. 64-67.

2. Finaeva, A.G. (2012) Resotsializatsionnyy potentsial sem'i osuzhdennogo [Resocialization potential of the convict's family]. ISOM. 4.

3. Shatrovoy, O.V. \& Kanchurina, A.A. (2014) Podkhody k penitentsiarnomu vospitaniyu kak sostavlyayushchey sotsial'nopsikhologicheskoy bezopasnosti [Approaches to penitentiary education as a component of socio-psychological security]. Molodoy uchenyy. 18. pp. 104-107. [Online]. Available from: https://moluch.ru/archive/77/13221/. (Accessed: 11.01.2018). 